\title{
LA UNIÓN ADUANERA Y SU IMPACTO EN LA ECONOMÍA CENTROAMERICANA
}

Aldair Portillo ${ }^{1}$

Jimena Bonilla ${ }^{2}$

\section{INTRODUCCIÓN}

El desarrollo económico de un país o región depende, entre otras cosas, de las decisiones que toman quienes ostentan la administración pública, basadas en los principios que rigen sus economías nacionales, y las políticas económicas desarrolladas en el ámbito nacional e internacional. Partiendo del aprovechamiento de los recursos existentes como primer supuesto, la capacidad de negociación y alianzas estratégicas entre países, como un mecanismo de consolidación en la economía local.

Empero, las políticas económicas de los países de una región, pueden tener un impacto más significativo cuando van orientadas al crecimiento del mercado y eliminación de obstáculos arancelarios o administrativos -impedimento para la inversión y generación de empleos-. Ejemplo de ello, son las políticas económicas implementadas mediante el proceso de integración sostenido entre Centroamérica y República Dominicana (SICA); el cual ha permitido crear vínculos económicos con la Unión Europea y países Sudamericanos, decisiones que han favorecido a la región de manera significativa, puesto que, se ha generado mayor inversión y apertura de los mercados internacionales, fortaleciendo las exportaciones y beneficiando a los productores locales.

Sin embargo, los tiempos actuales, obligan a los Estados a tomar mejores decisiones y adaptarse a las demandas de los consumidores y movimiento de los mercados, ante este supuesto, varios Estados han implementado la "Unión Aduanera", como un mecanismo de apertura al comercio exterior, esto, mediante la unificación de un sistema arancelario unificado y la eliminación de restricciones de carácter administrativo al flujo de mercancías.

\footnotetext{
${ }^{1}$ Pasante de Derecho e investigador de la Facultad de Ciencias Jurídicas de la Universidad Nacional Autónoma de Honduras. Correo: aldairportillo24@gmail.com

${ }^{2}$ Abogada, Master en Derecho Internacional, catedrática e investigadora en la Universidad Nacional Autónoma de Honduras, consultora internacional. Correo:jimena.bonilla@unah.edu.hn
}

DOI: https://doi.org/10.5377//rd.v40i1.8925
El objeto del presente texto es plasmar de manera clara, concisa y precisa las generalidades sobre el "Protocolo-habilitante" -Unión Aduanera entre Honduras, Guatemala y El Salvador-, estudiando sus antecedentes, contexto actual y sus incidencias en las economías de los Estados Partes. Presentando el análisis de las hipótesis sobre la factibilidad, retos, desafíos y su precepción en la región para los próximos años. Análisis que será abordado desde una óptica jurídico-económico.

\section{CONTEXTO}

Los países centroamericanos a lo largo de su historia se han caracterizado por mantener políticas económicas similares, a excepción de Panamá que se ha convertido en un paraíso fiscal lo que ha permitido que su economía se fortalezca con el paso del tiempo, contrario sen su, el resto ha mantenido políticas de subsistencia y programas económicos débiles; los cuales no se adaptan a las demandas de los mercados globales

Según FOSDEH (2017) "La inversión se nutre del dinamismo de la economía, que es la base para lograr un mayor crecimiento económico". En este supuesto, los tomadores de decisiones ostentores del poder tienen una imperante obligación y, es la búsqueda del desarrollo en sus naciones, intensión que se ha querido materializar desde la independencia de España a través de programas económicos, mismos que han fracasado en su intento, por la falta de innovación en las políticas económicas y la subsistencia de una visión conservadora.

En este sentido, la Comisión Económica para América Latina y el Caribe (CEPAL) revisó las proyecciones de crecimiento de la actividad económica de la región para 2018 y para 2019 se prevé una tasa de crecimiento del 1,8\%; para las economías de Centroamérica se estimó una tasa de crecimiento de $3,2 \%$ para el año 2018 y de 3,3\% para el 2019 .

Revista de Derecho. Vol. 40. No. 1. Año $2019 \mid-161$ 
En laactualidad, Centroamérica ha logradocambios muy significativos pues ha tomado a bien, algunas de las iniciativas desarrolladas en Asia del Pacifico, Norteamérica y la Europa occidental, modelos que van desde la creación de políticas públicas enfocadas a la inversión extranjera, programas económicos de acuerdo al contexto geográfico y, la creación de convenios internacionales en materia tributaria, para agilizar el comercio y generar mayores ingresos.

Empero, no solo es la inseguridad y violencia predominante en la zona, sino también los múltiples obstáculos que enfrentan los comerciantes e inversionistas que visitan la región, con el interés de invertir en la zona; lo que provoca el abandono y en su mayoría la quiebra de empresas. Ante esta situación, los tomadores de decisiones deben analizar el contexto y tomar de manera conjunta las mejores decisiones que conlleven a brindar seguridad jurídica a los inversores extranjeros.

Consecuentemente, los países Centroamericanos, han buscado las alternativas más viables que les permita lograr el desarrollo económico en la región, prueba de esa voluntad es la suscripción de los siguientes tratados marco: a) Protocolo al Tratado General de Integración Económica Centroamericana (Protocolo de Guatemala); b) Convenio de Compatibilización de tributos internos aplicables al comercio entre los Estados Partes de la Unión Aduanera Centroamericana; c) Convenio Marco para el Establecimiento de la Unión Aduanera Centroamericana; y, en el 2015 se da la suscripción del Protocolo-Habilitante: Por medio de este protocolo se contempla el establecimiento de la Unión Aduanera de los Territorios de la República de Guatemala y la República de Honduras; El Salvador se adhirió en los años siguientes.

De esta manera, se crea en el continente americano la primera unión aduanera con el objetivo de liberar la economía -aunque sea en teoría- de los países partes, mediante la creación de un sistema unitario de aranceles para ciertos productos, para evitar los impedimentos procesales, principalmente de los actos administrativos realizados por las a autoridades competentes, para poder ingresar y exportar productos a través del comercio.

La comunidad Europea del Carbón y el Acero marco un hito en los procesos de integración a nivel mundial, puesto que se convirtió en el experimento que dio fuerza a los procesos de integración de la Unión Europea. Así, el dinamismo de diferentes elementos de la integración conllevó a la creación de mejores condiciones en las economías de los países miembros, donde la expansión de mercados y unificación de la moneda trajo consigo múltiples ventajas.

En el mismo sentido, la Comisión Económica para América Latina (CEPAL) en las últimas décadas ha comenzado a promover la creación de políticas económicas encaminada a la industrialización de las economías locales, pertinente es mencionar en este contexto el caso de Brasil, el país con mayor en los procesos industriales y manufactura de la región. En consonancia con lo anterior, el Sistema de Integración Centroamericana (SICA) ha comenzado a experimentar una serie de acciones de carácter político y económico en aras de promover los flujos comerciales en el istmo y generar mejores oportunidades.

Empero, la promoción de dichas políticas no ha tenido en la mayoría de los casos, el éxito deseado, puesto que su efectividad depende de factores como la voluntad política de quienes ostentan el poder, del estudio y análisis de la geopolítica, aunque nos encontremos en la misma región; cada país tiene sus particularidades y estas deben ser atendidas en la creación de nuevas políticas económicas.

En datos de la CEPAL (2018), entre los países de Centroamérica, el arancel promedio aplicado para las importaciones de bienes es bajo (2\%). Sin embargo, existen costos asociados a carencias de infraestructura, así como a barreras administrativas que dificultan el aprovechamiento del mercado ampliado (cumplimentación de formularios aduaneros, tramitación de certificaciones Fito y zoosanitarias, requerimientos de empaque, inspecciones en diversos 
puntos del proceso exportador, entre otras). Ante las múltiples problemáticas comerciales suscitadas en las fronteras, las cuales provocaban el estancamiento del comercio y la no inversión en los países de la zona; Honduras y Guatemala deciden dar un paso a la creación de la unión aduanera.

El Protocolo-Habilitante en su convenio marco definió los puestos fronterizos integrados, que son "lugares ubicados en el territorio intrafronterizo de la Unión Aduanera en donde existen Centros de Control y Centros de Facilitación del Comercio, dentro de los cuales se aplican las disposiciones legales, reglamentarias y administrativas en materia aduanera, tributaria, migratoria, sanitaria y fitosanitaria, así como las demás materias involucradas, de cualquiera de los Estados Parte, entendiéndose que la jurisdicción $\mathrm{y}$ competencia de los órganos y funcionarios de cualquiera de los Estados Parte se considerarán extendidas hasta esas áreas". ${ }^{3}$

Las facilitaciones de estos centros de operación son:

a). Libre circulación de mercancías mediante Factura y Declaración Única Centroamericana FYDUCA;

b). Tránsitos aduaneros amparados en la DUT-C;

c). Control de paso de declaraciones de mercancías pagadas en aduanas periféricas;

d). Mercancías exceptuadas de la libre circulación. (FAUCA, DUT, DUA-DM), Permiso de turistas y FYDUCA de oficio.

En agosto de 2016, Oscar Ortiz, ex vicepresidente de El Salvador, entrego al Secretario General del SICA, Vinicio Cerezo, el Protocolo de adhesión de la República Salvadoreña a la unión aduanera, conformada por Honduras y Guatemala. Lo anterior se traduce como una muestra de buena voluntad política y constituye un avance significativo en la consolidación de la integración centroamericana.

El comercio fronterizo en la región centroamericana ha sido el problema de mayor impacto en los últimos años, lo que provoca que el comercio sea lento

\footnotetext{
${ }^{3}$ Unión Aduanera Guatemala, Honduras. Información General. Disponible en: file:///E:/INFORMACIÓN-GENERAL-UNIONADUANERA-GUATEMALA-HONDURAS.pdf
}

costoso, si se logra agilizar el comercio, se podrá fortalecer la integración económica; en este contexto el Protocolo habilitante viene a ser un mecanismo de mucho impacto y trascendencia; empero, aún siguen existiendo obstáculos y limitaciones comerciales en todos los sentidos.

De acuerdo con Herrera (2017), Conformar un régimen de unión aduanera, significa establecer un solo territorio aduanero que incluye un arancel común y la libre circulación de bienes, independientemente de su origen. Con base en los Protocolos y Convenios de la unión aduanera, las partes desarrollarán los procedimientos para la administración del régimen de libre circulación de mercancías y de personas entre los territorios de Honduras y Guatemala, pudiendo establecer, de manera temporal, excepciones al régimen de libre circulación.

De conformidad al artículo dos (2) del Convenio Marco para el establecimiento de la Unión aduanera Centroamericana, esta evolucionara de acuerdo al desarrollo de tres etapas a saber: a) promoción de libre circulación de bienes y facilitación del comercio; b) la modernización y convergencia normativa y; c) institucional. Metas que considero muy acertadas y con mucha visión.

Con la creación de la Unión Aduanera los países del triángulo norte de Centroamérica, han dado un paso al frente. Sin embargo, es necesario continuar trabajando de manera conjunta, con la mayor responsabilidad y compromiso en el cumplimiento de las obligaciones generales y específicas que se derivan de dicho instrumento jurídico. Lo anterior debe entenderse, como la adecuación de la legislación interna de cada país y la creación de las instrucciones especializadas que conlleven a la agilidad comercial y a la eliminación de la burocracia administrativa.

En este mismo pensar, la meta debe ser involucrar a todos los países que conforman el SICA, para ampliar la brecha en el área del comercio y la liberación o reducción de aranceles en el Itsmo, para aspirar con ello, a la consolidación de nuestras economías y convertirnos en futuro próximo en un área comercial más consolidada de América latina. Donde sus 
mayores ventajas serian la inversión extranjera, la creación de oportunidades laborales y la reducción de los flujos migratorios.

Si bien es cierto que muchos críticos han calificado la Unión Aduanera como un maquillaje o una fachada o un experimento sin futuro. También no es menos cierto, que los experimentos conllevan a grandes cambios si se saben planificar y ejecutar, asimismo, no es menos cierto, que la unión aduanera sigue avanzando paulatinamente y de manera integral, reduciendo procesos administrativos $\mathrm{y}$ aportando mayor facilidad y agilidad en la frontera.

La Unión Aduanera como se ha mencionado en párrafos precedentes, tiene como objetivo agilizar el comercio entre Guatemala, Honduras y el Salvador, acelerando los procesos administrativos y reduciendo costos fiscales. En lugar de duplicar dichos trámites y el papeleo en ambos lados de la frontera, ahora con un documento único llamado "FYDUCA" o lo que es igual a Factura y Declaración Única Centroamericana.

En la frontera, un lector de Código de Respuesta Rápida (Código QR) escanea instantáneamente el código de FYDUCA y certifica rápidamente, en línea, si el comprador (importador) ya pagó el impuesto al valor agregado sobre los bienes en el país de destino. En otras palabras, FYDUCA elimina los procedimientos aduaneros en las fronteras. A partir del 1 de marzo de 2018, ambos países hicieron obligatorio el uso de FYDUCA. El sector privado ahora puede comercializar el $80 \%$ de los productos de libre circulación entre ambos países de forma más rápida. Hay muchas razones para esperar que el comercio más rápido y más barato aumente su volumen, lo que generará una mayor variedad de productos más accesibles en el mercado y, por lo tanto, contribuirá al crecimiento económico de ambos países.

La unión aduanera representa en si: ${ }^{4} \mathrm{La}$ integración de sistemas informáticos entre ambos países que

\footnotetext{
4 Unión Aduanera Guatemala, Honduras. Información General. Disponible en: file:///e:/información-general-union-aduanera-guatemalahonduras.pdf
}

permitirán conocer la trazabilidad y mejor control de las operaciones aduaneras y tributarias. Significa fortalecer los sistemas de riesgo de fiscalización posterior en ambos países, ya que si bien es cierto se permite la facilitación, pero se fortalecen los controles aduaneros y tributarios, y uno de ellos es la fiscalización. Busca la integración de las actuaciones de las autoridades competentes que ejercen sus funciones en los puestos fronterizos integrados y aduanas periféricas en conjunto con las autoridades del otro país, en horarios homologados. Una oportunidad para mejorar y facilitar los procesos, lo que es demandado en el Acuerdo de Facilitación de Comercio de la OMC.

Según la Comisión económica de la CEPAL (2017) las ventajas de la unión aduanera se verán reflejadas en: Velocidad en el transporte: $16 \mathrm{~km} / \mathrm{h}$ (actual) a $30 \mathrm{~km} / \mathrm{h}$ (con la unión), Mejora y expansión de infraestructura y corredores logísticos, Fomento para la competitividad del país, Promoción de la convergencia de los sistemas tributarios, Promoción de sectores estratégicos y de atracción de inversión, Fortalecimiento del proceso de integración regional, Eficiencia en comercio y la Reducción de un 21 a 25\% de costos logísticos, que involucran tiempo y unidades monetarias.

Aún quedan muchos desafíos por superar, tales como: empresas que necesitan capacitación, problemas con la infraestructura, inconvenientes con los sistemas de ambos países, conocimiento insuficiente de los nuevos procedimientos, entre otros. Pero, con el paso del tiempo se irá mejorando a partir de las experiencias y de la voluntad política de los Estados partes.

Esta unión aduanera debe ser visionada para la adhesión de todos los países centroamericanos, México y Colombia como puntos clave del comercio por su ubicación geográfica, para poder optar por una economía centroamericana emergente en la región y con ello lograr ser competitivos en los mercados globales 


\section{CONCLUSIONES}

1. La región centroamericana se ha caracterizado por la exportación de productos primarios, hacia el interior del país y mercados internacionales, e importadora de bienes y servicios manufacturados de países como Norteamérica, la Europa occidental y Asia de Pacifico. Es clara, entonces, la inoperatividad de contar con un sistema arancelario único en la región, que permita aumentar el ingreso económico de manera más ágil y eficaz.

2. Siendo Centroamérica una región exportadora de materia primaria, es solo natural concluir que una de las causas de su atraso económico relativo, es consecuencia de las políticas exteriores desarrolladas en las últimas décadas; las cuales carecen de innovación a los tiempos actuales, el alto costo de aranceles y los múltiples trámites administrativos que dilatan de manera significativa el flujo del comercio en la zona y la apertura de nuevos mercados.

3. La unión aduanera entre Honduras, Guatemala y El Salvador ha sido la mejor decisión de los Estados Partes, como un mecanismo de dinamizar el comercio en la zona, estimulando los diferentes sectores de las economías nacionales, ampliando los mercados, incentivando las inversiones internacionales y generando mayores empleos en la zona.

4. En el caso del Protocolo Habilitante, existe la probabilidad de lograr una unión aduanera con todos los países del Istmo centroamericano y República Dominicana, que permita el crecimiento económico de la región a grandes escalas y se posicione como una de las economías emergentes de la región; lo anterior, en un plazo medio, todo dependerá de la voluntad política de los gobernantes.

5. La unión aduanera ha traído consigo, múltiples ventajas para la región, quien en cifras de la CEPAL su economía ha crecido notablemente, los trámites administrativos en las aduanas se han reducidos y a la vez, se han agilizado dichos procesos; aunado a ello, la fijación de un sistema arancelario único para los productos que entran en esta categoría -liberación o reducción arancelaria según el protocolo- han permitido que las economías se fortalezca y que se avance de manera conjunta, viéndose beneficiados de manera directa productores y ciudadanos de manera general de cada uno de los países partes.

6. Los países del triángulo norte, que hasta el momento mantienen esta unión aduanera en la región Centroamérica deben manifestar su voluntad política, mediante el diálogo y negociación para incorporar a los demás países de la región y así poder lograr mayor crecimiento del comercio de manera más ágil y con menos costos.

7. Se deben de crear los programas de capacitación de manera virtual, que permita al interesado conocer los procedimientos y generalidades del nuevo sistema aduanero para las empresas que comercializan en la zona y para las que desean invertir en la región.

\section{BIBLIOGRAFÍA}

- FOSDEH (2017). Inversión Pública: la ruta del desarrollo. Recuperado de: http://www.fosdeh. com/wp-content/uploads/2017/02/inversion publica -la ruta del desarrollo sostenible.pdf.

- CEPAL (2018). Estudio Económico de América Latina y el Caribe. Recuperado de: https://repositorio.cepal.org/bitstream/ handle/11362/43964/141/S1800837 es.pdf.

- Espinoza, E. T. (2008) La comunidad europea del carbón y del acero. Un exitoso y aún inacabado experimento institucional. Anuario Mexicano de Derecho Internacional, vol. VIII, pp. 713-742.

- CEPAL (2018). La Unión Aduanera Centroamericana: probables impactos económicos $y$ sociales. Recuperado de: https://www.cepal. Revista de Derecho. Vol. 4O. No. 1. Año 2019 -165 


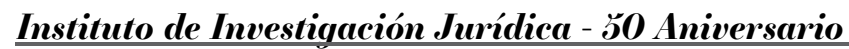

org/sites/default/files/events/files/la union aduanera centroamericana probables impactos economicos y sociales 1.pdf.

- CEPAL (2018). Información general de la Union Aduanera Honduras Guatemala. Recuperado de: $\quad$ file:///C:/Users/ACER-/Downloads/ INFORMACI\%C3\%93N-GENERAL-UNIONADUANERA-GUATEMALA-HONDURAS. pdf.

- Herrera, Juan de Dios. (2018) Consortium LegalHonduras. La unión aduanera Centroamericana. Recuperado de: http://consortiumlegal. com/blog/2018/11/08/la-union-aduaneracentroamericana/.

- CEPAL. (2017) Posibles efectos económicos y sociales de la profundización de la Unión Aduanera entre Guatemala y Honduras. Recuperado de: https://www.cepal.org/es/publicaciones/41849posibles-efectos-economicos-sociales-laprofundizacion-la-union-aduanera. 